\title{
STUDY OF THE BEHAVIOURS OF SINGLE-PHASE TURBULENT FLOW AT LOW TO MODERATE REYNOLDS NUMBERS THROUGH A VERTICAL PIPE. PART I: 2D COUNTERS ANALYSIS
}

\author{
Akeel M. Ali Morad \\ Department of Fuel and Energy ${ }^{l}$ \\ akeel@stu.edu.iq \\ Rafi M. Qasim \\ Department of Fuel and Energy ${ }^{l}$ \\ rafi.mohammed@stu.edu.iq \\ Amjed Ahmed Ali \\ Department of Fuel and Energy \\ amjedoet@stu.edu.iq \\ Engineering Technical College \\ Southern Technical University \\ Alzubair Highway Str. - In front of Basra Sport City, Basra-Iraq, 61001
}

\begin{abstract}
This study presents a model to investigate the behavior of the single-phase turbulent flow at low to moderate Reynolds number of water through the vertical pipe through (2D) contour analysis. The model constructed based on governing equations of an incompressible Reynolds Average Navier-Stokes (RANS) model with $(k-\varepsilon)$ method to observe the parametric determinations such as velocity profile, static pressure profile, turbulent kinetic energy consumption, and turbulence shear wall flows. The water is used with three velocities values obtained of $(0.087,0.105$, and $0.123 \mathrm{~m} / \mathrm{s})$ to represent turbulent flow under low to moderate Reynolds number of the pipe geometry of $(1 \mathrm{~m})$ length with a $(50.8 \mathrm{~mm})$ inner diameter. The water motion behavior inside the pipe shows by using [COMSOL Multiphysics 5.4 and FLUENT 16.1] Software. It is concluded that the single-phase laminar flow of a low velocity, but obtained a higher shearing force; while the turbulent flow of higher fluid velocity but obtained the rate of dissipation of shearing force is lower than that for laminar flow. The entrance mixing length is affected directly with pattern of fluid flow. At any increasing in fluid velocity, the entrance mixing length is increase too, due to of fluid kinetic viscosity changes. The results presented the trends of parametric determinations variation through the (2D) counters analysis of the numerical model. When fluid velocity increased, the shearing force affected directly on the layer near-wall pipe. This leads to static pressure decreases with an increase in fluid velocities. While the momentum changed could be played interaction rules between the fluid layers near the wall pipe with inner pipe wall. Finally, the agreement between present results with the previous study of [1] is satisfied with the trend.
\end{abstract}

Keywords: Single-phase Turbulent Flow, Low to Moderate Reynolds Numbers, Vertical Pipe.

DOI: $10.21303 / 2461-4262.2020 .001538$

\section{Introduction}

Many industrial applications involve axis-symmetric geometries (i. e. pipes, diffusers, cyclones, etc.) and complex two-dimensional flows with unsteady flow phenomena. The turbulence models often fail to accurately simulate the turbulent motion and heat exchange in these kinds of applications, because of the insensitivity of Reynolds-Averaged Navier-Stokes equations (RANS) to unsteady flow features. Modeling of higher correlations of the shear-rate and vortices tensor can account for additional physical effects, such as streamline curvature, however, it cannot able to alleviate general problems involved with this numerical method. If the fluid has significant yield stress or the effective viscosity is high, industrially relevant flow rates may occur in the laminar flow regime.

However, in some cases, the flow can be turbulent so, thus there are advantages in operating pipe flow in a transitional flow regime. This can lead to the lowest specific energy consumption. The majority of pipe single turbulent flow numerical simulations to date have studied stability. 
Relatively few direct numerical simulations have been few performed of turbulent flows at high Reynolds number. A technique used to achieve a higher resolution to measure the turbulent flow of water through the pipe is presented by [1]. They used the Reynolds number range 5,000 to 25,000 to determine the mean velocity profile, turbulence intensity scales, and shear stress near the wall of the pipe. In their results, they found that the inner layer near the pipe wall, which is the flow geometry, is not important inflows of low Reynolds numbers. They proposed a future investigation of the variables of turbulent flow from low to moderate Reynolds numbers.

The extreme Reynolds number of turbulent flow inside the pipe was experimentally presented by [2]. The archived their work by using a new technique (scale thermal anemometry probe) to determine the pressure and velocity profile of airflow inside the super-pipe. A three-dimensional direct numerical simulation method used for turbulent mean flow with Reynolds number range from 2,250 to 5,900 is presented by [3]. The fully developed turbulent pipe flow which used a secondorder-accurate finite difference method for Reynolds number up to 6,950 was presented by [4].

The Reynolds number of upstream based on velocity friction velocity was obtained through the universal logarithmic law of the wall studied by [5]. These studies were all based on the study of [6], which presents finite-amplitude axis-symmetric disturbances, however, their results remain controversial. Also, they investigated the non-linear stability of pipe flow guided by their theory of secondary instability. They found that all axis-symmetric finite-amplitude disturbances decay but non-axis-symmetric disturbances can be strongly unstable. The two-dimensional incompressible low to moderate Reynolds number used a Navier-Stokes equation for the velocity gradient for boundary element functions. For Reynolds numbers above 1,000, the resolved formulation converges and becomes stable [7]. The fluid flow behavior may show within the pressure drop profile to single-phase flow for the laminar and turbulent flow $[8,9]$. They measured pressure drop experimentally for the inner pipe diameter of $(0.026 \mathrm{~m})$ with an airflow rate of $\left(0.02 \mathrm{~m}^{3} / \mathrm{s}\right)$. The results showed that the pressure drop for laminar flow is less than that of the turbulent flow for the same pipe geometry. They used the RANS model with $(k-\varepsilon)$ model and large eddy simulation to numerically solve the models. They obtained that the time solved in large eddy simulation is greater by 100 times for the RANS model.

Eventually, $[10,11]$ proved that the high-pressure oscillation $n$ two-phase flow than in single-phase flow. They demonstrated the experiment rig to test the section of the tube of $(250 \mathrm{~mm}$ length and $1.5 \mathrm{~mm}$ inner diameter). In contrast, [12] presented the eddy-viscosity model with three additional transport equations. Their model was implemented with the computational fluid dynamic (CFD) for the pressure gradient over a flat plate. They demonstrated the model for turbulent flow to resolve by average Reynolds number. The obtained results showed that the model can be used for practical tools for engineers. The flow of fluid at Low Reynolds Number (LRN) based on Partially Averaged Navier-Stokes (PANS) for the near-wall turbulent modeling was presented by [13]. Their study of two Reynolds numbers used (10600 and 37000) for channel flow. The results show that the PANS model diverged from the RANS model for a channel turbulent flow. Recently, the numerical simulation of fluid flows by using a turbulent flow through the elbow depending on Reynolds number was presented by [14]. Their study showed that the turbulent flow is solved by standard $(k-\varepsilon)$ method with the RNG model, and standard wall function for a vertical pipe of length $3.35 \mathrm{~m}$ with 90 elbows. Their obtained turbulent model gives a good behavior for stream velocity profile[15] presented a numerical investigation of non-Newtonian fluid flowing through a circular pipe. Their study employed laminar, steady incompressible flow, and the results show that the entrance length for laminar flow is directly affected by increases in Reynolds number.

This study introduces the mechanical behavior of transition flow through a pipe of non-normality of the liberalized Navier-Stokes equations in cylindrical 2D coordinates that are expected to predicate the Reynolds number effects for turbulent pipe flow. From the opened literature, a single-phase turbulent flow of the RANS model with $(k-\varepsilon)$ method is not wild generalized for fluid flow through vertical pipe (single) phase, especially through the counters' analysis. The CFD techniques were used to numerically model the state of single-phase turbulent flow through a vertical pipe. The upward flow of liquids in vertical pipes suffers from many flow parameters which then affect the quality of the flow and, on the other hand, directly affect the pumping motor, causing more power to be consumed. 


\section{Governing Equations}

The governing equations are the incompressible Navier-Stokes equations, which in the rotational form are [15]:

$$
\begin{gathered}
\frac{\partial v}{\partial t}+w \times v=-\nabla p+v \nabla^{2} v, \\
\nabla \cdot v=0 \text { in } \Omega,
\end{gathered}
$$

where $v=(u, v)$ is the velocity field $u, v$ refer to streamwise, radial and azimuthal velocity components, respectively $P=p+1 / 2 v$. $v$ is the total pressure, $\omega=\nabla \times v$ is the vorticity, and $v$ is the kinematic viscosity.

The discrimination of the equations is performed using spectral methods. Since the objective is the investigation of infinite pipe flow, Fourier expansions are introduced in the streamwise and azimuthal directions for all flow variables.

$$
u_{(z, r, \varphi, t)}=\sum_{k=0}^{K-1} \sum_{m=0}^{M-1} u_{m, k}(r, t) e^{i m \varphi} e^{i \alpha k z},
$$

where $m$ represents azimuthal Fourier modes, $k$ streamwise modes, and $\alpha=\left(L_{Z} / 2\right) \pi$ the streamwise wave number. Substituting expansion equation (3) in the governing equations, and applying the following change of variables to obtain on [16]:

$$
\tilde{v}_{m k}=v_{m k}-i \omega_{m k} ; \quad \tilde{\boldsymbol{\omega}}_{m k}=v_{m k}-i w_{m k}
$$

The system of equations is:

$$
\begin{aligned}
& \frac{\partial \overline{v_{m k}}}{\partial t}+\mathfrak{I}_{m k}(\omega \times V)_{r}=-\left(\frac{\partial P_{m k}}{\partial_{r}}-\frac{m}{r} P_{m k}\right)+v\left(\nabla_{r z}^{2}-\frac{(m+1)^{2}}{r^{2}}\right) \overline{v_{m k}}, \\
& \frac{\partial \overline{\omega_{m k}}}{\partial t}+\mathfrak{I}_{m k}(\omega \times V)_{\varphi}=-\left(\frac{\partial P_{m k}}{\partial_{r}}-\frac{m}{r} P_{m k}\right)+v\left(\nabla_{r z}^{2}-\frac{(m-1)^{2}}{r^{2}}\right) \overline{v_{m k}}
\end{aligned}
$$

and

$$
\begin{gathered}
\nabla_{r z}^{2}=\frac{1}{r} \frac{\partial}{\partial r}\left(r \frac{\partial}{\partial r}\right)-\alpha^{2} k^{2}, \\
\mathfrak{I}_{m k}(\omega \times V)_{r}=\mathfrak{I}_{m k}(\omega \times V)_{r}+i \mathfrak{I}_{m k}(\omega \times V)_{\varphi}, \\
\mathfrak{I}_{m k}(\omega \times V)_{\varphi}=\mathfrak{I}_{m k}(\omega \times V)_{r}-i \mathfrak{I}_{m k}(\omega \times V)_{\varphi},
\end{gathered}
$$

where $\mathfrak{I}_{m k}$ refers to a Fourier transform in both $\varphi$ and $z$. The coordinate singularity at $r=0$ is removable since it can be shown that the behavior of the Fourier coefficients of the velocity components close to the axis is:

$$
\begin{gathered}
\left(u_{m}, v_{m}, w_{m}\right) \propto\left(\beta r^{m}, \gamma r^{m-1}, i \gamma r^{m-1}\right), \\
v_{m k}+i \omega_{m k} \propto r^{m+1},
\end{gathered}
$$

where $\beta$ and $\gamma$ are constants.

It can be verified $\tilde{v}_{m k}=v_{m k}-i w_{m k}$ that is zero at $r=0$ for all $\mathrm{m}$ and it scales like the latter is equivalent to the fact that the vortices are also regular at $r=0$. On the other hand, the variable $\tilde{\tilde{\omega}}_{m k}=v_{m k}-i w_{m k}$ has a non-zero value at $r=0$ for $m s=1$; however, the coefficient of $\tilde{\mathscr{\omega}}_{m k}$ for $m=1$ is zero and so the singularity in (4c) is removed.

The set of polynomials employed close to the axis corresponds to the Jacobi polynomials $P$, with associated weights which are zero at $r=0$. 


\section{Modeling formulation}

\section{1. Turbulent Flow of Reynolds Averaged Navier-Stokes Model}

From a structure point of view, RANS speaks to a sensible trade-off between precision and rate, and various specialists have created expectation techniques for limit layer change. The least difficult RANS-based methodology is the non-modeled LRN whirlpool thickness choppiness models, which have been utilized for an expectation of transitional streams with some level of achievement.

\section{2. Turbulent Flow $k-\varepsilon$}

The model considered turbulent flow for LRN of a fluid of incompressible flow in a vertical pipe of length $(L)$ and radius $(r)$. The fluid flowed upward under the influence of the kinetic and dissipation rate of turbulent kinetic energies supplied from the bottom of the pipe. The $2 \mathrm{D}$ cylindrical system coordinate is shown in Fig. 1.

\section{Graphics}

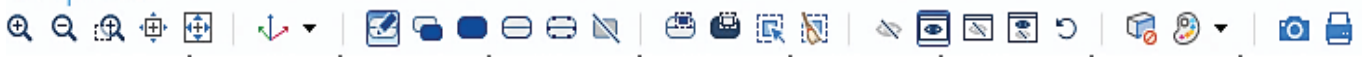

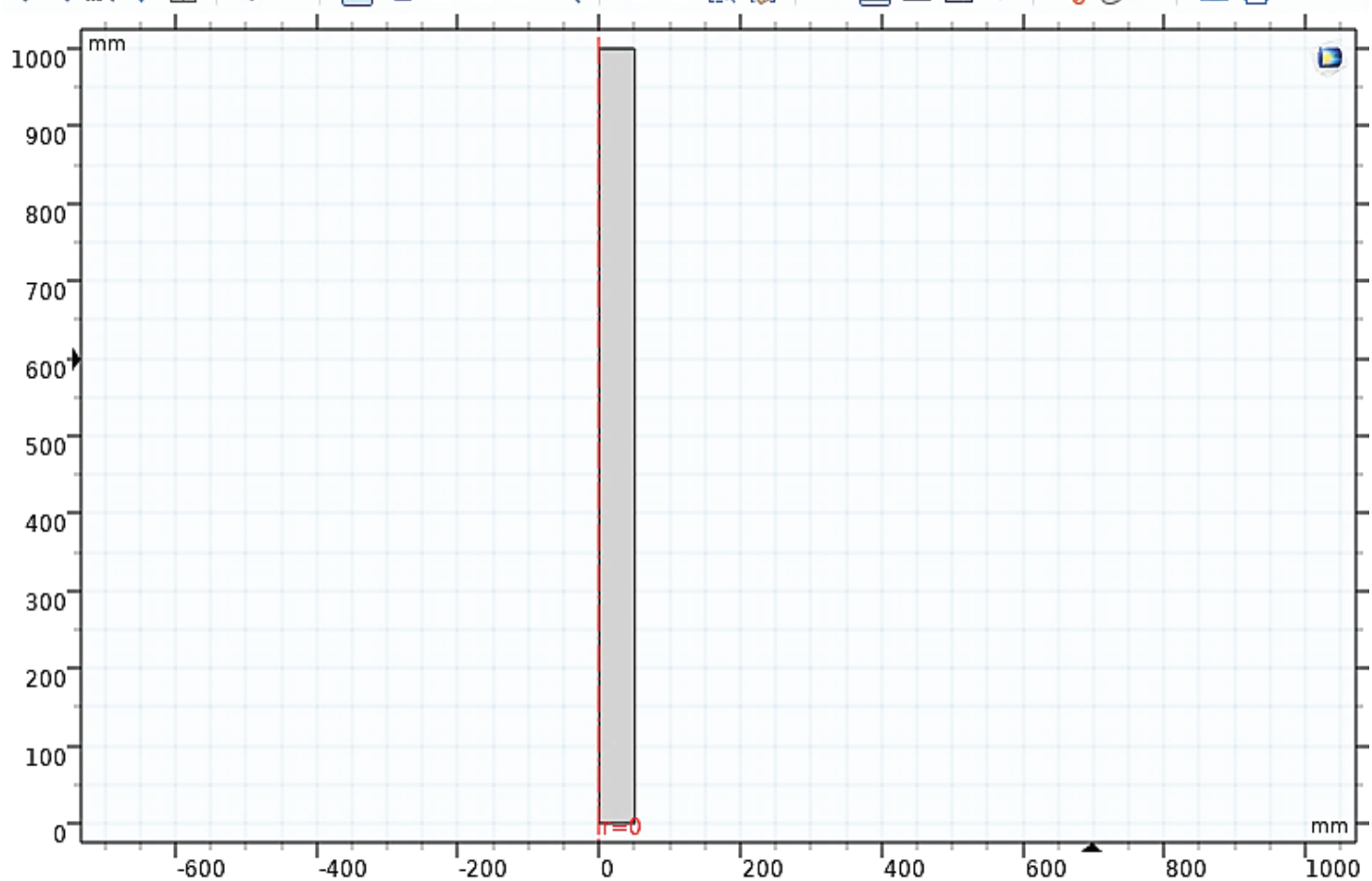

Fig. 1. 2D cylindrical system coordinates

The pipe geometry specified that the pipe length is very large concerning the pipe radius.

$$
\begin{gathered}
\rho(u \cdot \nabla) u=\nabla \cdot[-p I+K]+F+\rho g, \\
\nabla \cdot(\rho u)=0, \\
K=\left(\mu+\mu_{T}\right)\left(\nabla_{u}+\left(\nabla_{u}\right)^{T}\right)-\frac{2}{3}\left(\mu+\mu_{T}\right)\left(\nabla_{u}\right)-\frac{2}{3} \rho K I, \\
\rho(u \cdot \nabla) K=\nabla \cdot\left[\left(\mu+\frac{\mu_{T}}{\sigma_{K}}\right) \nabla K\right]+P_{K}-\rho_{\int}, \\
\rho(u \cdot \nabla) \int=\nabla \cdot\left[\left(\mu+\frac{\mu_{T}}{\sigma_{j}}\right) \nabla \int\right]+C_{\int 1} \frac{\int}{K} P_{K}-C_{\int 2 \rho} \frac{\int 2}{K}, \quad \int=e p,
\end{gathered}
$$




$$
\begin{gathered}
\mu_{T}=\rho C_{\mu} \frac{K^{2}}{\int}, \\
P_{K}=\mu_{T}\left[\nabla u:\left(\nabla u+(\nabla u)^{T}\right)-\frac{2}{3}(\nabla \cdot u)^{2}\right]-\frac{2}{3} \rho K \nabla \cdot u .
\end{gathered}
$$

The above relations discussed the Turbulent Kinetic Energy $(K)$ with momentum viscosity fluid changes of the field flow.

\section{Computational Domain Test}

The above model was tested for water with a solid cylinder domain of $(r, L$, and $Z)$ coordinates, and then this model implemented ding a commercial CFD module of COMSOL Multiphysics 5.4 software (Build: 295) with ANSYS FLUENT 16.1 software was used to solve this case with a 2D drawing of the pipe geometry. The pipe geometry was $1 \mathrm{~m}$ length with a $50.8 \mathrm{~mm}$ inner diameter. The streamflow assumed turbulent flow of three inlets' Reynolds numbers were used to test the model of $(4945,5969$, and 6992). The geometry was analyzed for 2D-axis-symmetric mashing with (21014 nodes and 18997 elements) as shown in Fig. 2.

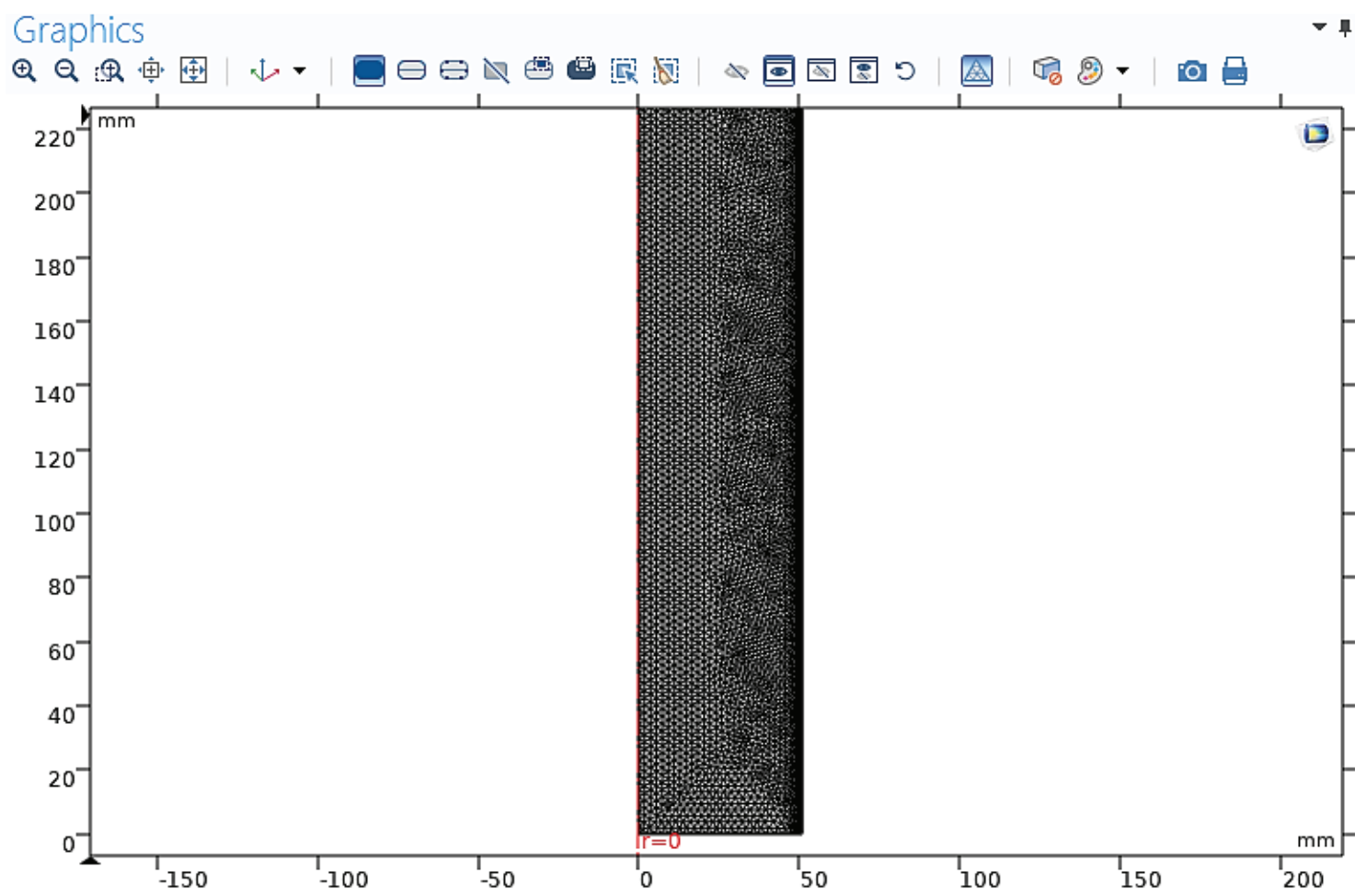

Fig. 2. 2D axis-symmetric mesh

The geometry drawing with bottom inlet water upward through a vertical pipe. The inflation is five layers with $(k-\varepsilon)$ method of (RANS) model. The value distance of the first layer from the inner pipe wall is $0.001 \mathrm{~m}$.

\section{Results and Discussions}

The profile of velocity and pressure distributions in turbulent upward water flow was obtained using a RANS model at various Reynolds numbers.

\section{1. Comparison between Laminar and Turbulent Single Flow with RANS Model}

The main difference between the laminar and turbulent single flow at fully developed status was observed with the quantities of the viscous effect and thick layer of fluid near the pipe wall. 
The inside pipe wall worked as damping for the energy balance of fluid flowing through it. The velocity of the fluid directly affects the wall shear stress, which forms due to the viscous force. Fig. 3 shows the cross-section shear stress rate for laminar and turbulent single flow in the pipe, which is programmed by ANSYS FLUENT software, $a$ - for laminar flow and $b$ - for turbulent flow, both for water with the same properties. While Fig. 3 clearly shows the impact of the layer thickness near the pipe wall on the prediction of the changing flow behavior. Thus, one can conclude that the rate of deformation of the fluid layer increases for laminar flow and decreases in turbulent flow [19].
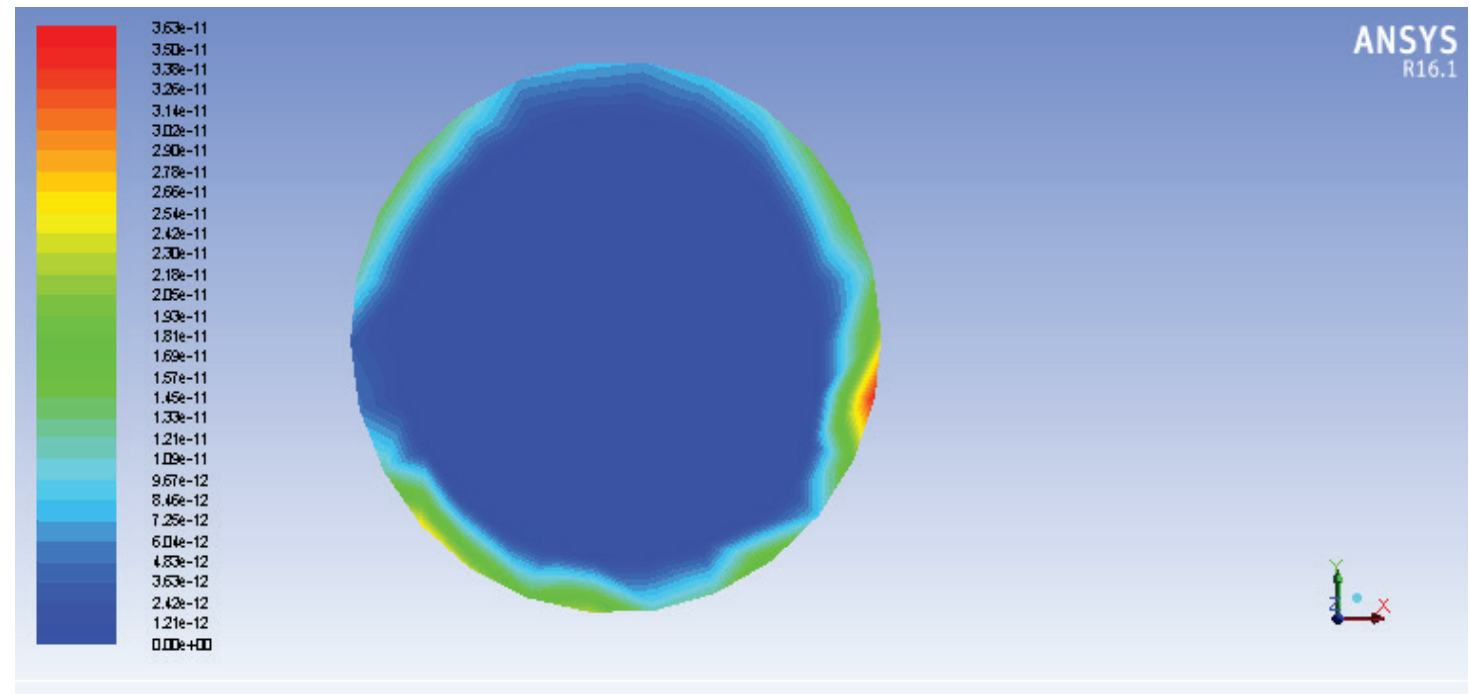

Contours of Wiall Shear Stress (pascal)

Oct 10,2019

$a$

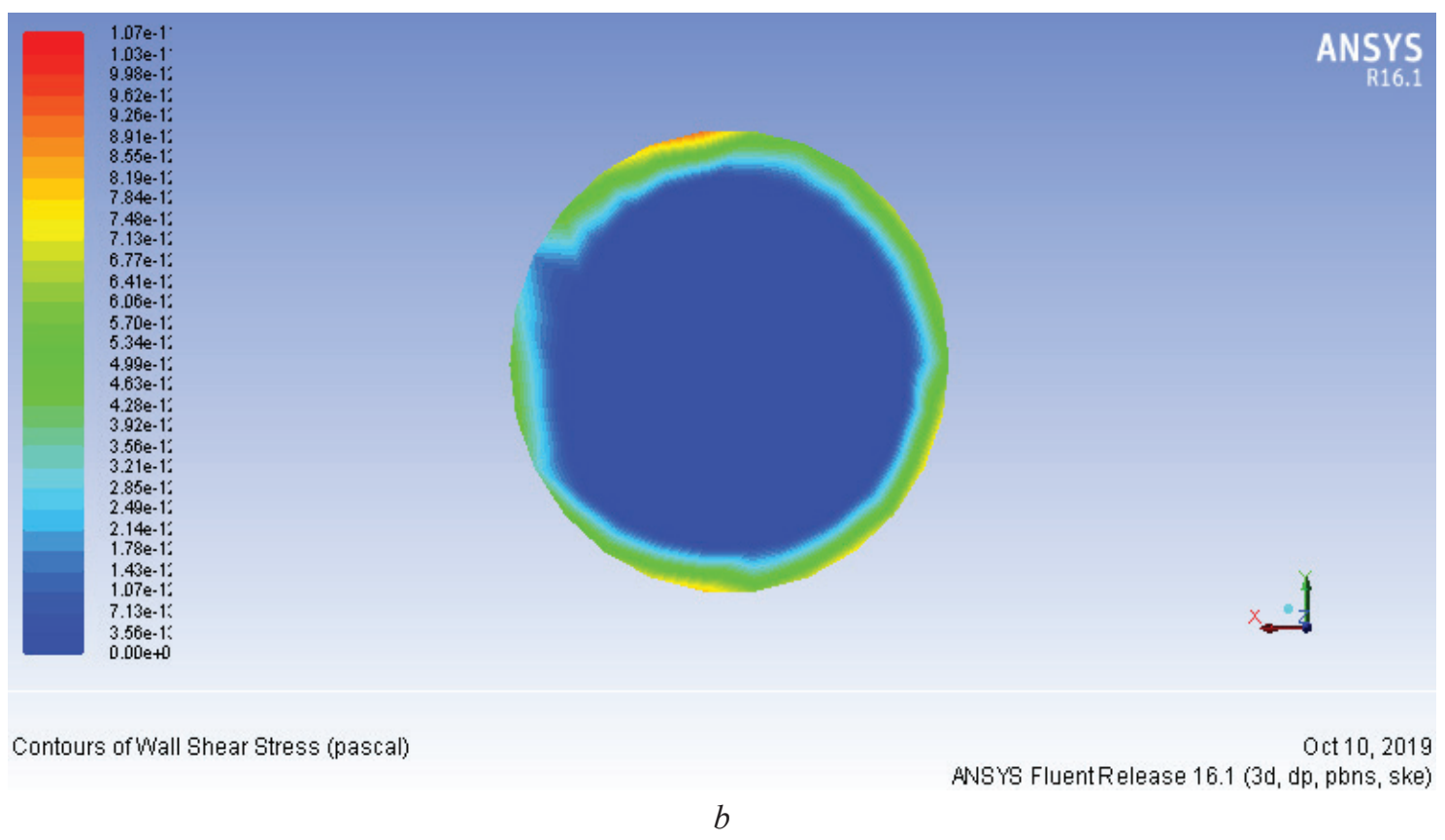

Fig. 3. Wall shear stress of the layer near the pipe wall: $a$ - laminar flow, $b$ - turbulent flow

Fig. 4 shows the wall shear stress at turbulent flow. The obtained data of the present work was compared with the previous work of [1]. The effect of the viscous force of the liquid layer near the pipe wall is increased due to $(r / d)$ approaching the value of 1 (i. e. the radius $(r)$ becomes closer to the inner tube diameter $(d)$ of the pipe). 


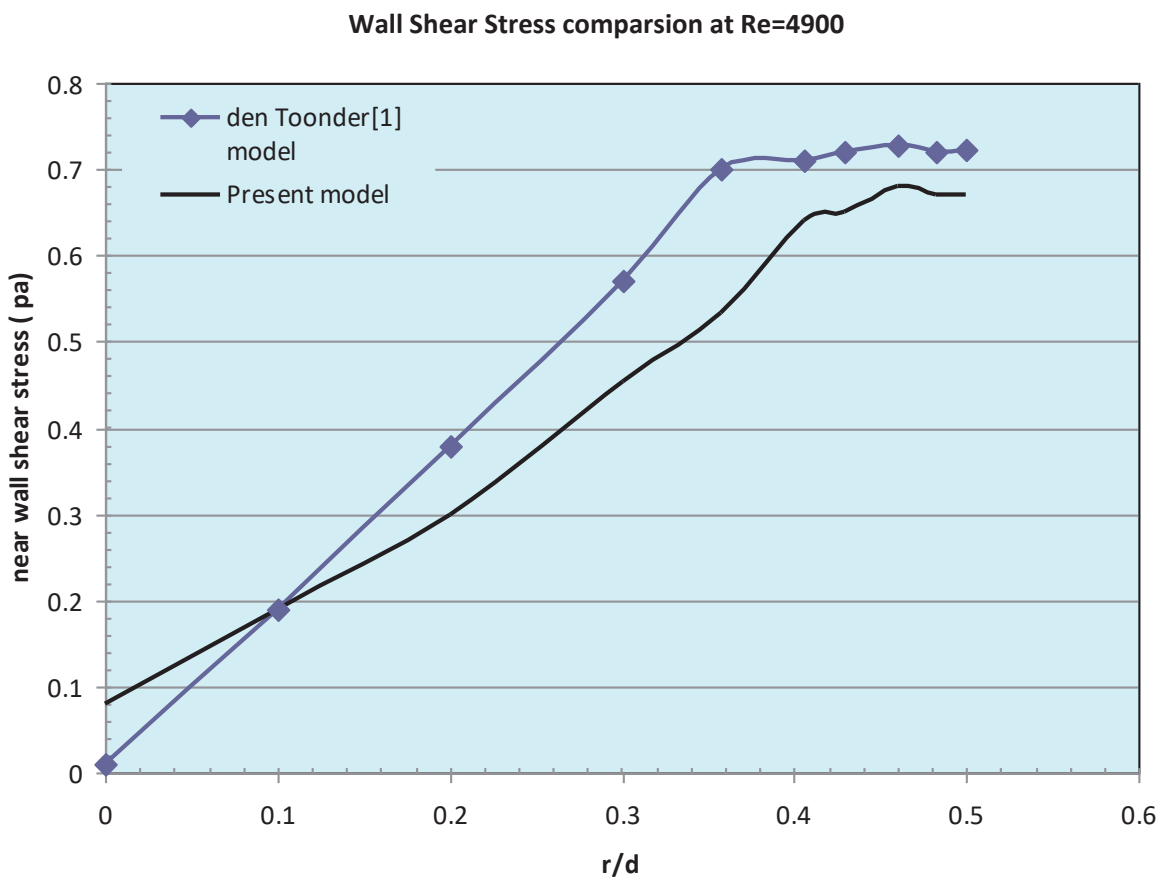

Fig. 4. Near wall shear stress of turbulent flow of water compared with provirus work

Now, the present work is given a good agreement when the shear stress remains slightly constant at the pipe wall layer.

\section{1. 1. Velocity Profile}

Fig. 5 shows the changes in the velocity profile of the single-phase turbulent flow of liquid (water) along a vertical pipe modeled by COMSOL Multiphysics 5.4. From this Fig. 5, it is clear that the fluid properties may vary normally to the flow due to the local values of viscosity and density. Again in this Fig. 5, the velocity value is $(0.087 \mathrm{~m} / \mathrm{s})$, and the entrance turbulent region is not for fully developed flow until the fluid has traveled from the entrance until the length of pipe which start-up to form the wall boundary layer, which is called entrance mixing length $\left(l_{E}\right)$, and can be expressed as by [13]:

$$
l_{E}=\sqrt{\frac{\tau}{\rho v^{2}}},
$$

where

$$
v^{2}=\frac{d^{2} v}{d y^{2}} .
$$

Increasing the velocity of the fluid to $(0.105 \mathrm{~m} / \mathrm{s})$ can lead to integrate the velocity profile at lower entrance mixing length and as shown in Fig. 5. The velocity distribution of fluid is directly affected by pipe walls, which lead to deformation at less time after the entrance to the pipe. When fluid velocity is increased to $(0.123 \mathrm{~m} / \mathrm{s})$, the entrance mixing length formed quickly as shown in Fig. 6 . One can conclude that the increasing velocity of the fluid at the entrance leads to entrance mixing length forming after less time of the fluid traveling. At the water velocity of $(0.087 \mathrm{~m} / \mathrm{s})$, the fully developed region starts to form at a mixing length of approximately $(0.20 \mathrm{~m})$; for the velocity of $(0.105 \mathrm{~m} / \mathrm{s})$, the mixing length started to form at entrance length of approximately $(0.15 \mathrm{~m})$; and for a velocity of $(0.123 \mathrm{~m} / \mathrm{s})$, the mixing length became approximately $(0.10 \mathrm{~m})$.

Fig. 6, $\boldsymbol{a}-\boldsymbol{c}$ show the (2D) cross-section velocity profile plane at a fully developed region of velocities of $(0.087,0.105$, and $0.123 \mathrm{~m} / \mathrm{s}$ respectively). As these show, at any increase in velocity, the boundary layer thickness becomes thinner, because the shear and friction forces decrease due to increasing fluid velocity. Moreover, at continuous flow velocity at the center of the pipe, the shearing forces become less and lead to a higher velocity. 


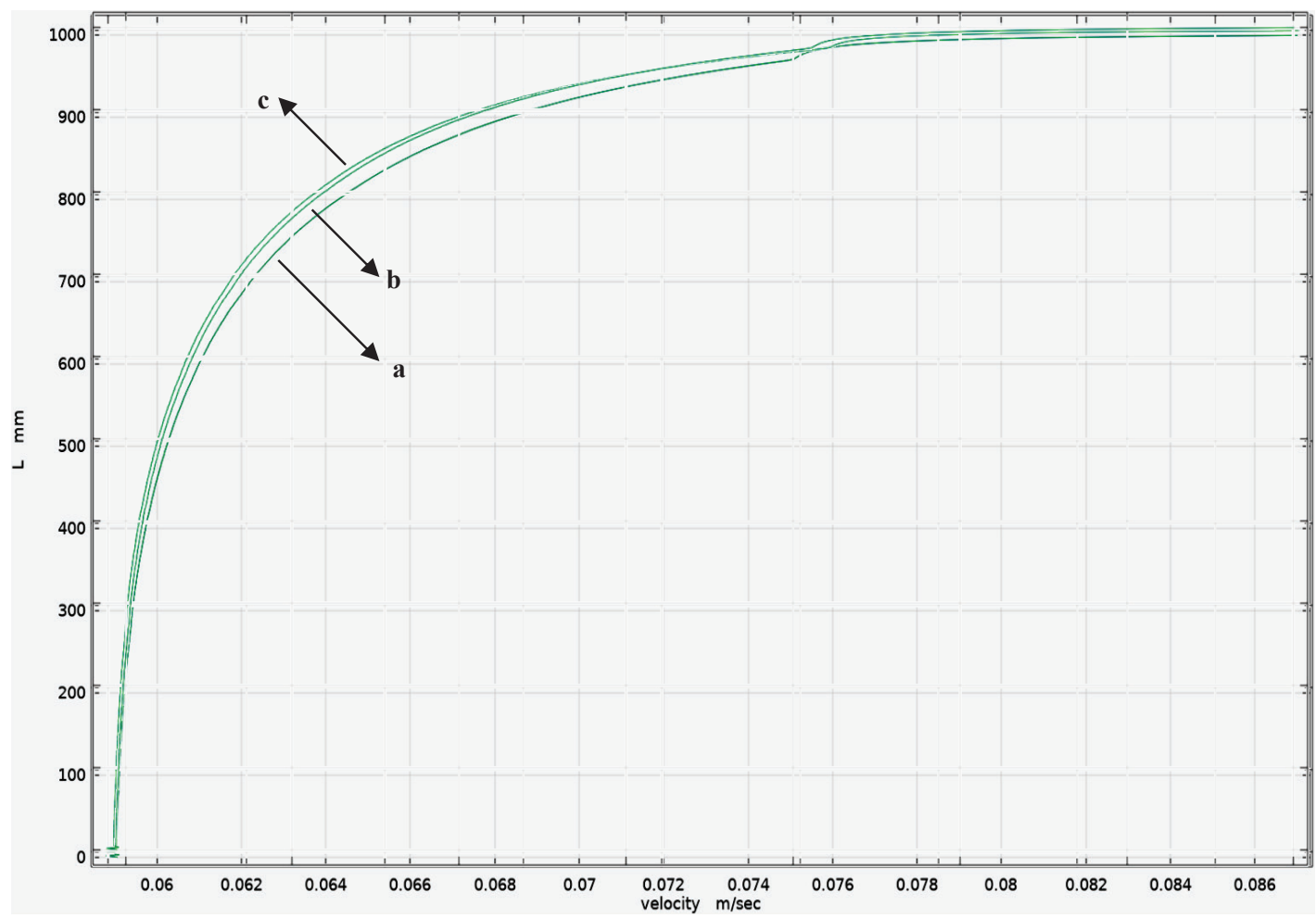

Fig. 5. Single-phase turbulent upward flow in vertical pipe at: $a-v=0.087 \mathrm{~m} / \mathrm{s} ; b-v=0.105 \mathrm{~m} / \mathrm{s} ; c-v=0.123 \mathrm{~m} / \mathrm{s}$

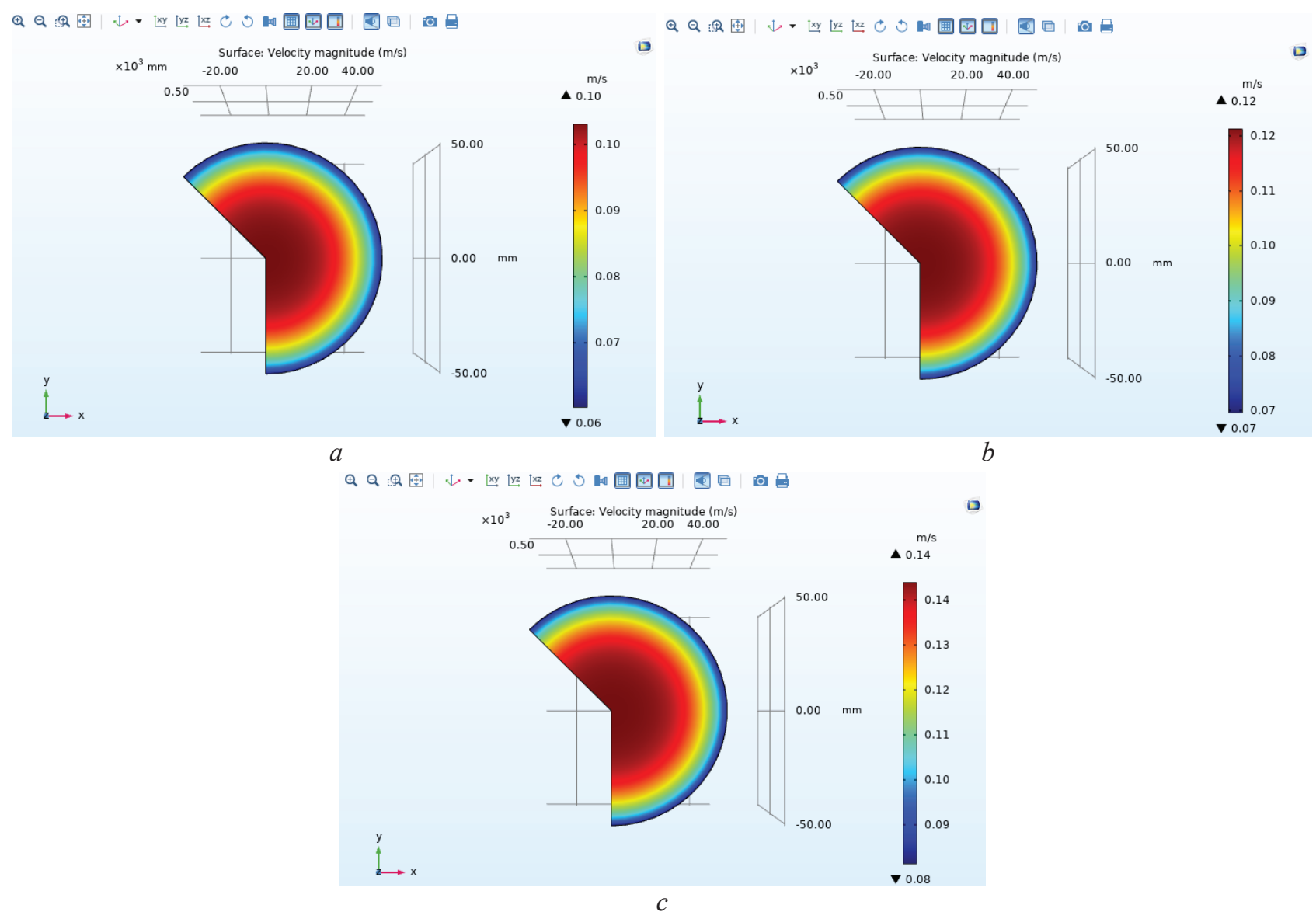

Fig. 6. 2D velocity profile plane: $a-0.087 \mathrm{~m} / \mathrm{s} ; b-0.105 \mathrm{~m} / \mathrm{s} ; c-0.123 \mathrm{~m} / \mathrm{s}$ 
Fig. 7, $\boldsymbol{a}-\boldsymbol{c}$ show the (2D) velocity profile at the fully developed region of cross-section vertical pipe at three fluid velocities of $(0.087,0.105$, and $0.123 \mathrm{~m} / \mathrm{s}$, respectively).

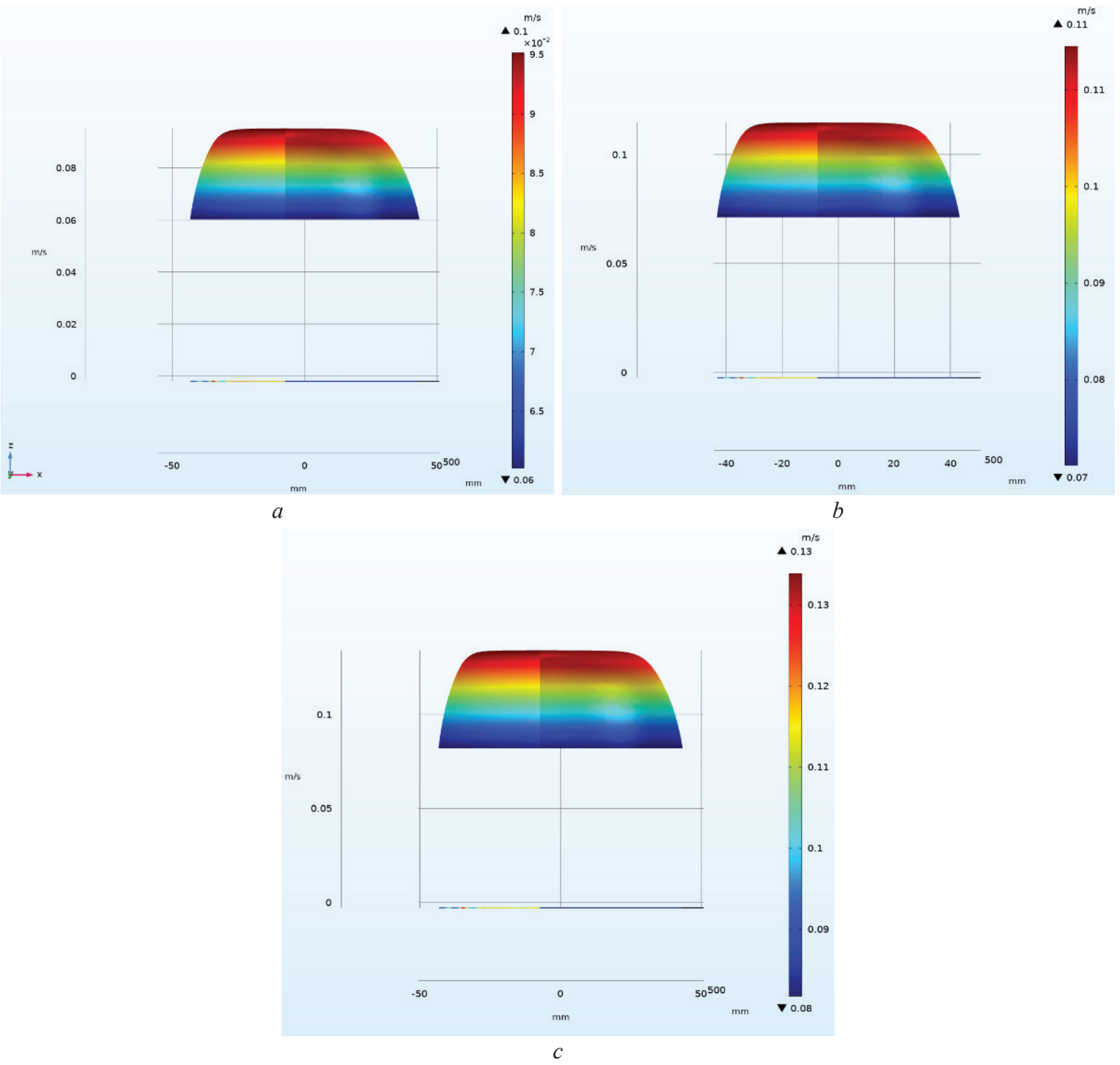

Fig. 7. Velocity profile at fully developed region for vertical pipe at:

$$
a-0.087 \mathrm{~m} / \mathrm{s} ; b-0.105 \mathrm{~m} / \mathrm{s} ; c-0.123 \mathrm{~m} / \mathrm{s}
$$

From these above Fig. 7, it can seem that when the fully developed velocity profile forms at a higher value of fluid flow velocity, the pressure distribution will deform the velocity profile.

\section{1. 2. Mean Velocity Profile}

The normalized mean fluid velocity flowing upward in the vertical pipe may suffer the problem of the near-wall fluid layer.

This layer appears to be irrespective of the Reynolds number for a single flow. The centerline fluid velocity turbulent flow is varied with the direct influence of the Reynolds number. The normalized near-wall fluid layer thickness $\left(Y^{+}\right)$of the turbulent flow ranging from 50 to 800 is 
as cited in $[1,2,4]$. The constructed correlation equation to predicate the wall layer velocity $\left(U^{+}\right)$ is as follows:

$$
\begin{gathered}
U^{+}=2.5 \mathrm{LN}\left(\mathrm{Y}^{+}\right)+5.5[1], \\
U^{+}=4.837+1.078 \mathrm{LN}(\mathrm{Re})[2] .
\end{gathered}
$$

Fig. 8 shows the comparison of the obtained data with previous work by using the above correlations. At increases in the dimensionless wall layer $\left(Y^{+}\right)$the mean velocity is increased too, corresponding with [1]; whereas increases in the Reynolds number lead to increases in the mean velocity too, due to the upward flow of fluid moving.

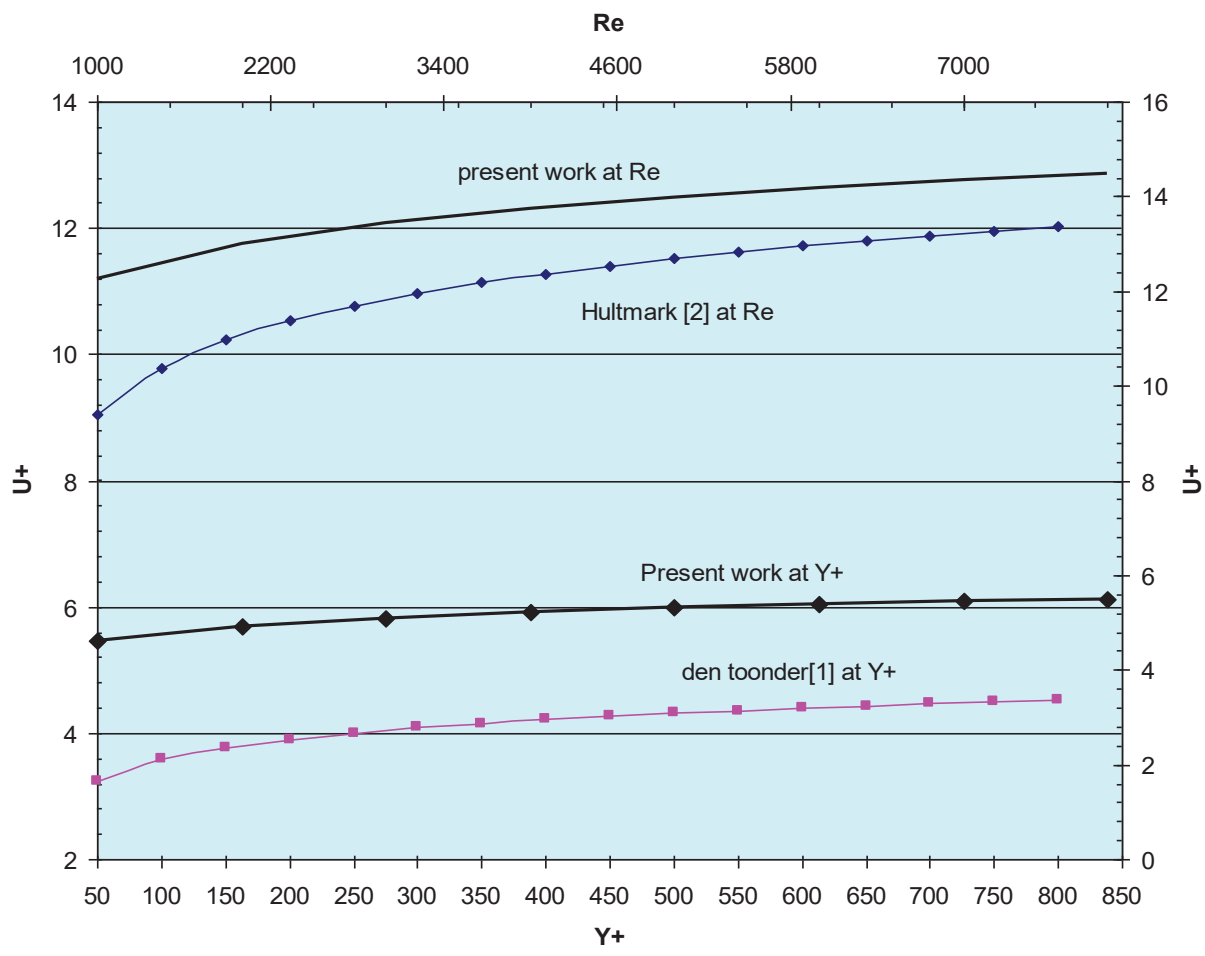

Fig. 8. Mean velocity profile of the fluid layer

Again, Fig. 8 shows the distribution of the mean velocity of inside vertical pipe when compared with previous works. The present work curve trend showed mean velocity distribution various directly with Re number, due to the shearing force formation inside pipe. While, the boundary layer thickness verity trend less, thus because of the stability of low and moderate turbulent flow.

\section{2. Pressure Profile}

To predict the behavior of a single turbulent flow through vertical pipes of the pipe wall, the prior studies showed that the sensitive parameter of the most direct influence on the flow model is the pressure gradient. This pressure is affected by factors such as inner wall surface type, Reynolds number, gravity force, friction factor, and the shear stress deformed due to fluid contact with pipe wall roughness.

Fig. 9-14 explains the static and dynamic pressure profiles through the vertical pipe for turbulent single-phase flow of liquid at different inlet velocities of $(0.087,0.105$, and $0.123 \mathrm{~m} / \mathrm{s}$, respectively). These Fig. 9-14 clearly show that the higher value of pressure rises at the bottom and the pressure values become lower at the top of the pipe, due to the velocities changing along the pipe. 


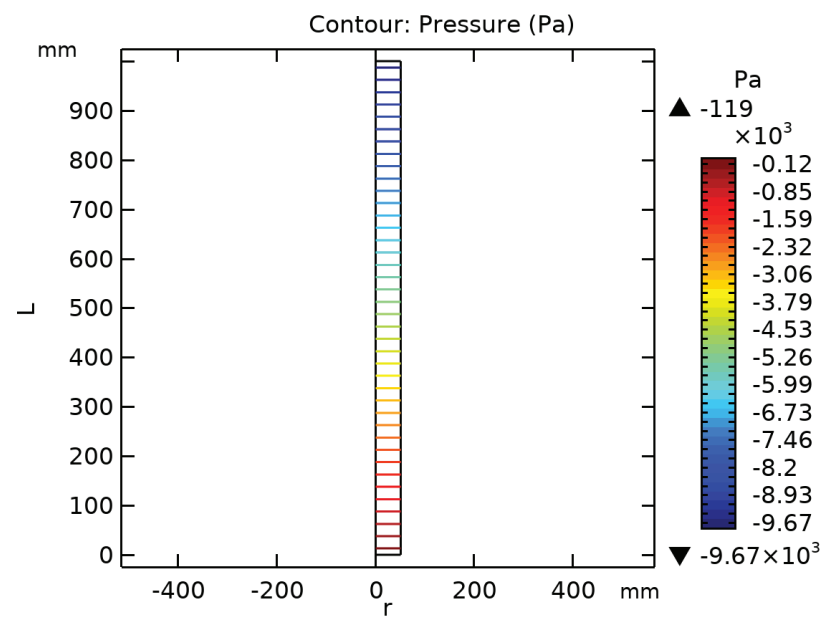

Fig. 9. Static pressure profile (Pascal) along vertical pipe at $v=0.087 \mathrm{~m} / \mathrm{s}$

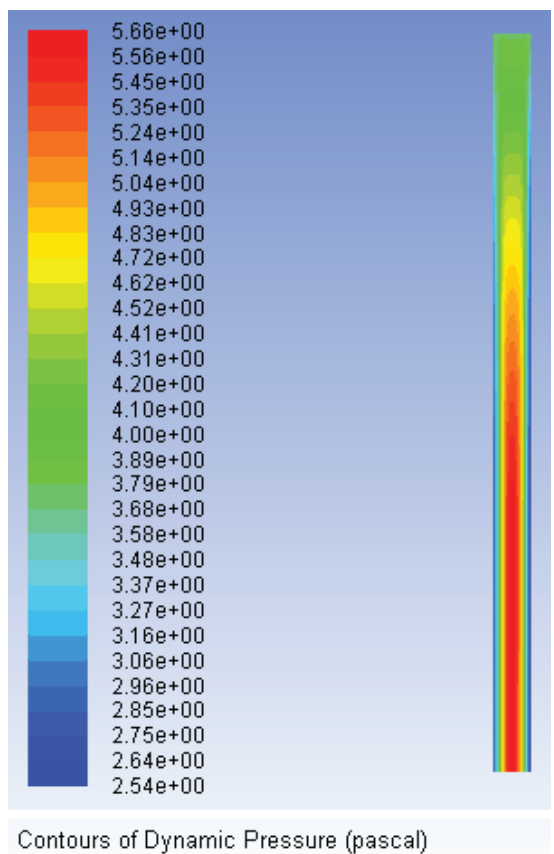

Fig. 10. Dynamic pressure profile (Pascal) along vertical pipe at $v=0.087 \mathrm{~m} / \mathrm{s}$

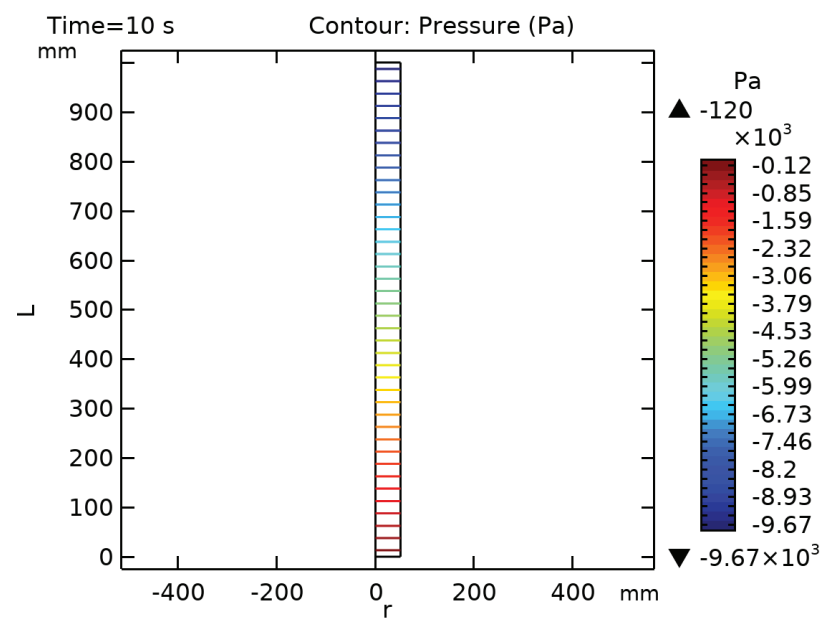

Fig. 11. Static pressure profile (Pascal) along vertical pipe at $v=0.105 \mathrm{~m} / \mathrm{s}$ 


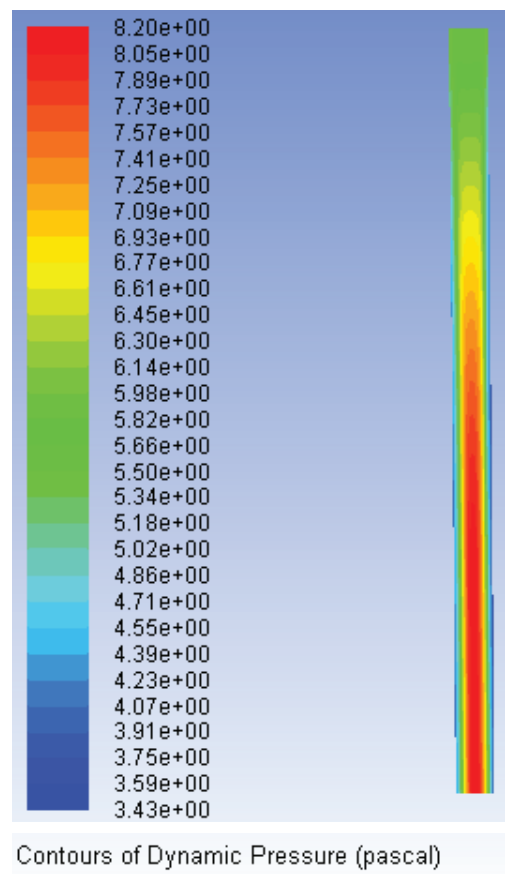

Fig. 12. Dynamic pressure profile (Pascal) along vertical pipe at $v=0.105 \mathrm{~m} / \mathrm{s}$

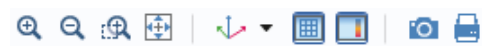

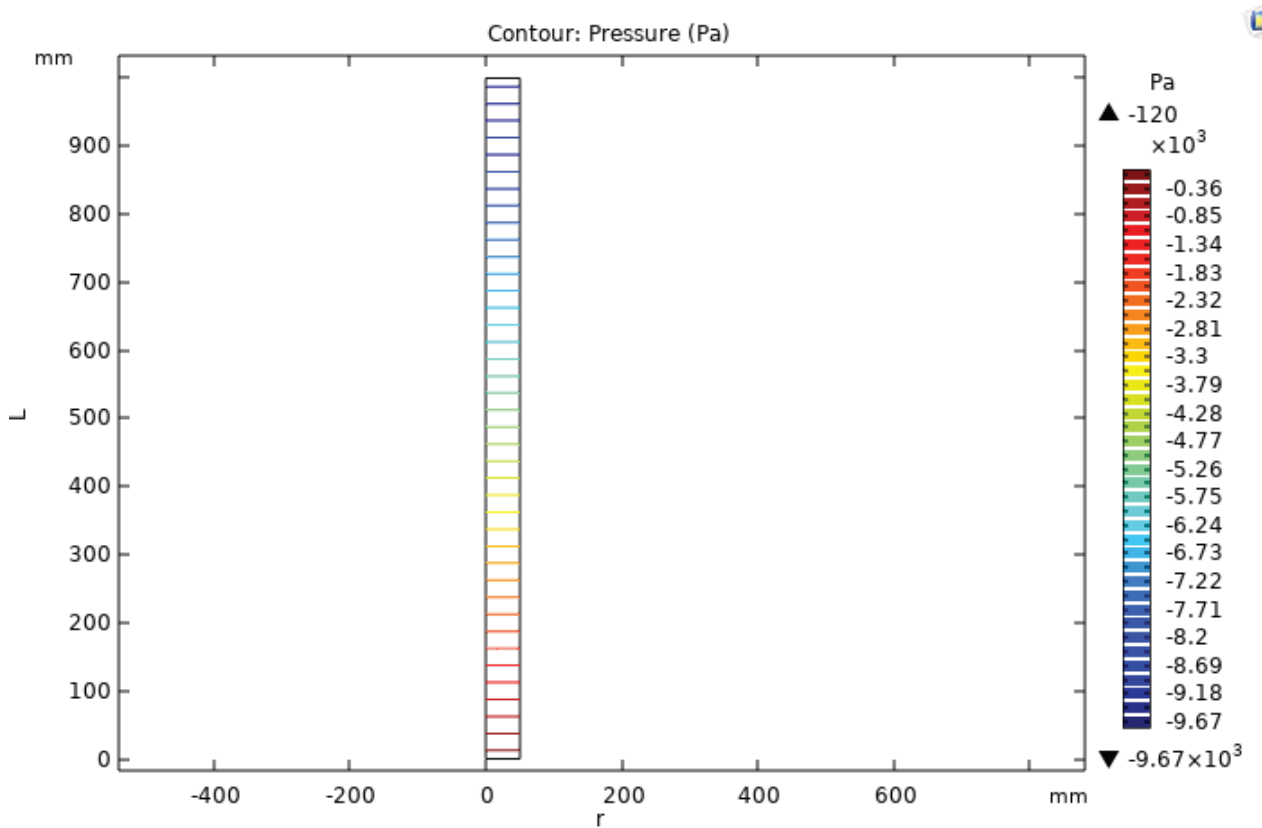

Fig. 13. Static pressure profile (Pascal) along vertical pipe at $v=0.123 \mathrm{~m} / \mathrm{s}$

Fig. 15 explains the static pressure variation with pipe length to the inner pipe diameter $(l / d)$ ratio at a given water flow velocity through the vertical pipe.

The maximum value of the static pressure was obtained at the entrance velocity of the fluid at $(l / d=20)$ due to the minor friction region, while the static pressure decreases at a given fluid velocity. When the fluid velocity increases the static pressure decreases due to the lower value of the friction region.

The obtained data of this study were compared with the previous work of [2]. The present work shows the dynamic behavior of static pressure inside the pipe. 


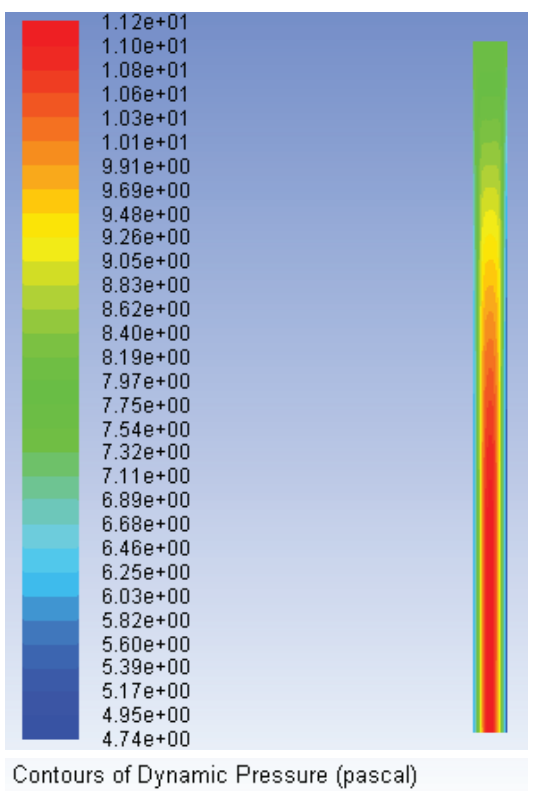

Fig. 14. Dynamic pressure profile (Pascal) along vertical pipe at $v=0.123 \mathrm{~m} / \mathrm{s}$

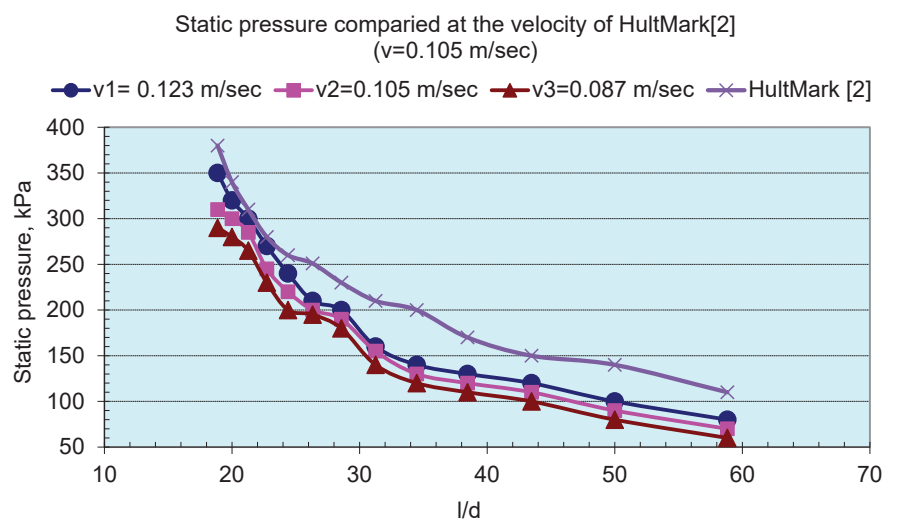

Fig. 15. Static pressure variation with $(l / d)$ ratio at three fluid velocities

\section{3. Turbulent Kinetic Energy}

Due to the high-velocity spectra of the fluid flow inside the conducted pipe, the turbulent kinetic energy $(K)$ occurred through the fluid single flow together with a relatively thin layer nearwall of the pipe at a constant temperature. Fig. 16, $\boldsymbol{a}-\boldsymbol{c}$ clearly show that any increase in the fluid velocity the $(K)$ was increased. Thus, it seems like the momentum changed near the pipe wall and gradually dissipated in the direction of the flow core. In Fig. 16, $\boldsymbol{a}$, at a velocity of $(0.087 \mathrm{~m} / \mathrm{s})$, the core flow region inside the pipe is relatively narrow, while the core flow region becomes wider with the increase in flow velocity, as illustrated in Fig. 16, $b, c$.

\section{4. Turbulent Wall Shear Flows}

The spectrum of turbulent energy of the flow is directly affected by the viscous drag of the fluid layer near the pipe wall. The turbulent viscosity of fluid property, especially of liquids, works as the deflector to the velocity profile. Fig. 17, $\boldsymbol{a}-\boldsymbol{c}$ show the change of the turbulent viscosity along with the upward flow of water through the vertical pipe. At low velocity, the turbulent viscosity showed a regular velocity profile as shown in Fig. 17, $\boldsymbol{a}$, at the velocity of $0.087 \mathrm{~m} / \mathrm{s}$, and the length of the straight viscosity streamline is relatively shorter than with the increase in the velocity, as shown in Fig. 17, $\boldsymbol{b}$ at the velocity of $0.105 \mathrm{~m} / \mathrm{s}$ and Fig. 17, $\boldsymbol{c}$ at the velocity of $0.123 \mathrm{~m} / \mathrm{s}$.

The above Figures clearly show the deflection of the streamline to the fluid flow is fluctuated at the entrance region (the bottom of the pipe), due to the viscous drag force and the fluid pressure impacts. 


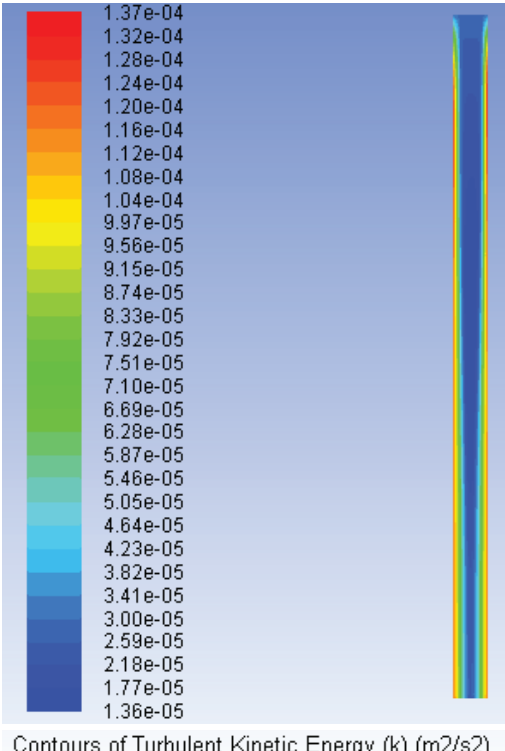

$a$

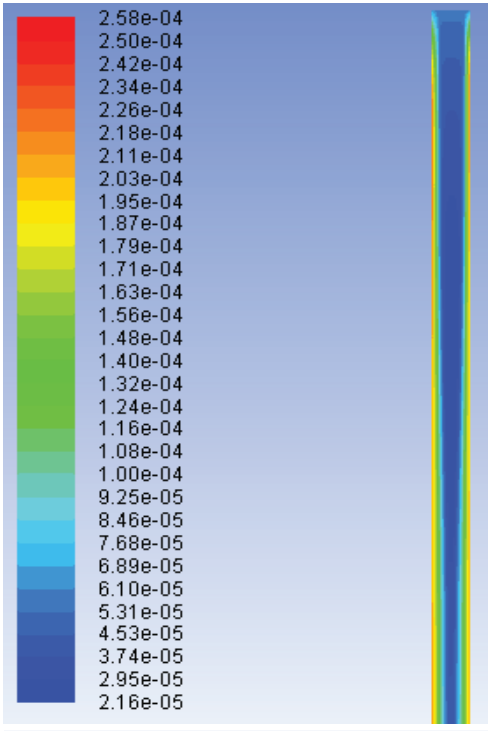

Contours of Turbulent Kinetic Energy $(k)(\mathrm{m} 2 / \mathrm{s} 2)$ $b$

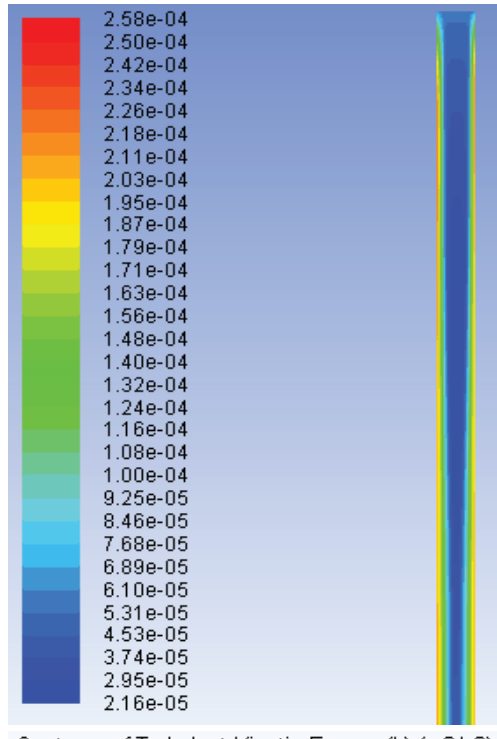

Contours of Turbulent Kinetic Energy ( $k$ ) (m2/s2) c

Fig. 16. Turbulent Kinetic Energy through pipe at: $a-0.087 \mathrm{~m} / \mathrm{s} ; b-0.105 \mathrm{~m} / \mathrm{s} ; c-0.123 \mathrm{~m} / \mathrm{s}$

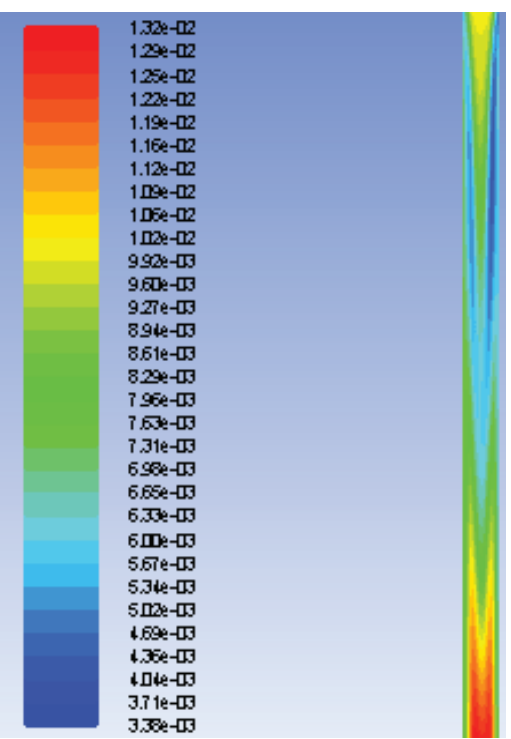

Contours of Turbulent Viscosity (kgim-s)

$a$

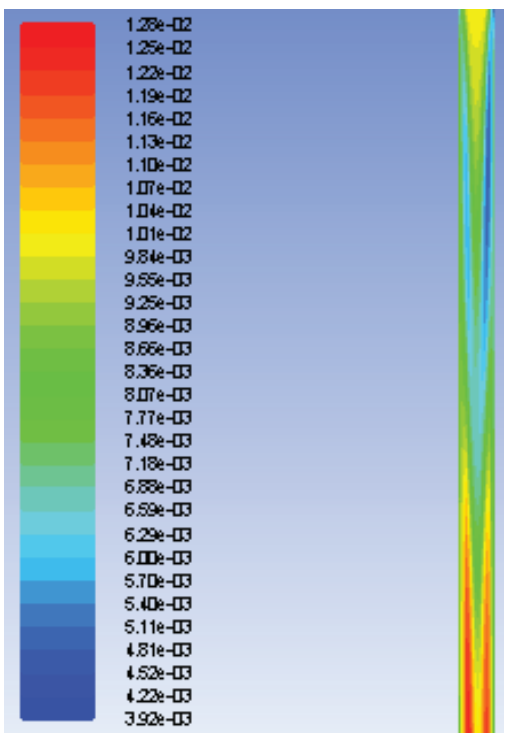

Contours of Turbulent Viscosity (kgim-s)

b

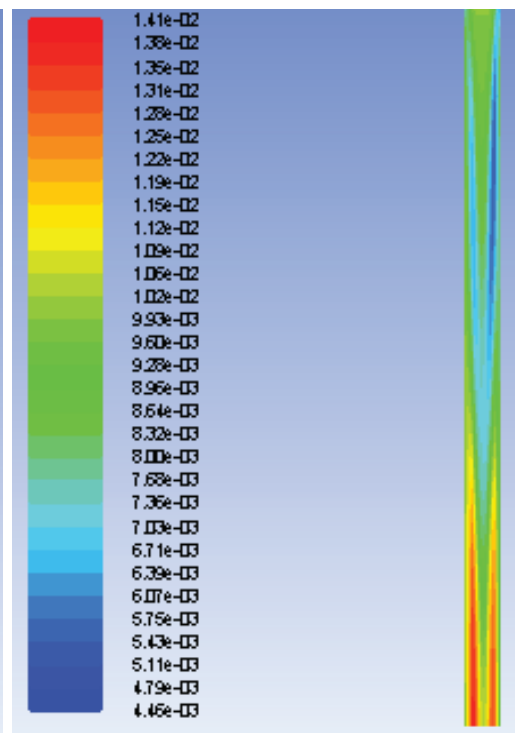

Contours of Turbulent Viscosity (kg/m-s)

Fig. 17. Turbulent viscosity through pipe at: $a-0.087 \mathrm{~m} / \mathrm{s} ; b-0.105 \mathrm{~m} / \mathrm{s} ; c-0.123 \mathrm{~m} / \mathrm{s}$

The study used the water as a fluid flowing in a vertical pipe. The flow is single-phase turbulent with two limitations of Reynolds Number (as mentioned in abstract). Used the model constructed of an incompressible Reynolds Average Navier-Stokes (RANS) model with $(k-\varepsilon)$ method. 2D simulation of water domain to study the behavior of water flowing inside the pipe shows by [COMSOL Multiphysics 5.4 and FLUENT 16.1]. Many parameters were focused to determine the flow behavior of fluid flowing such as (fluid velocity, pressure, shear stress, kinetic energy, etc).

\section{Conclusion}

1. The velocity profile is directly affected by the shearing force of the liquid layer near the pipe wall, and gradient velocity value at balance is the fully developed region. The distance from the fluid entry is determined by entrance mixing length for three fluid velocities, obtained with a pipe of $1 \mathrm{~m}$ length and $50.8 \mathrm{~mm}$ inner diameter. 
2. The static pressure drop indicates the amount of fluid acting as a body force inside the pipe combined with shearing forces acting on the liquid layer near the pipe wall, while dynamic pressure drop represents the velocity of the fluid to overcome the gravitational force-resisting upward flow.

3. The momentum change of the fluid is shown by the turbulent kinetic energy, which indicates the forces of the single-phase flow of liquid layer near the pipe wall.

4. One of the important parameters is the shearing force, which becomes more complex with turbulent flow. The interaction between the liquid flow and the pipe wall obstructs streamflow.

5. The laminar single-phase flow is a low velocity, but it can obtain a higher shearing force; while turbulent flow is obtained at a higher fluid velocity but the rate of dissipation of shearing force is lower than that for laminar flow.

\section{References}

[1] Den Toonder, J. M. J., Nieuwstadt, F. T. M. (1997). Reynolds number effects in a turbulent pipe flow for low to moderate Re. Physics of Fluids, 9 (11), 3398-3409. doi: https://doi.org/10.1063/1.869451

[2] Hultmark, M., Vallikivi, M., Bailey, S. C. C., Smits, A. J. (2012). Turbulent Pipe Flow at Extreme Reynolds Numbers. Physical Review Letters, 108 (9). doi: https://doi.org/10.1103/physrevlett.108.094501

[3] Nikitin, N. V. (1993). Direct three-dimensional numerical simulation of turbulence and transition in a pipe-Poiseuille flow. In Bulletin of APS, 38 (12), 2311.

[4] Unger, F., Eggels, J. G. M., F'reidrich, R. (1993). On second and higher-order statistics in fully-developed turbulent pipe-flow. In Proc. 9th Symp. on Turbulent Shear Flows. Kyoto.

[5] Davey, A., Nguyen, H. P. F. (1971). Finite-amplitude stability of pipe flow. Journal of Fluid Mechanics, 45 (4), $701-720$. doi: https://doi.org/10.1017/s0022112071000284

[6] Aydin, M., Fenner, R. T. (2001). Boundary element analysis of driven cavity flow for low and moderate Reynolds numbers. International Journal for Numerical Methods in Fluids, 37 (1), 45-64. doi: https://doi.org/10.1002/fld.164

[7] Spedding, P. L., Benard, E., Mcnally, G. M. (2008). Fluid Flow through 90 Degree Bends. Developments in Chemical Engineering and Mineral Processing, 12 (1-2), 107-128. doi: https://doi.org/10.1002/apj.5500120109

[8] Moghaddas, J. S., Trägårdh, C., Östergren, K., Revstedt, J. (2004). A Comparison of the Mixing Characteristics in Singleand Two-Phase Grid-Generated Turbulent Flow Systems. Chemical Engineering \& Technology, 27 (6), 662-670. doi: https:// doi.org/10.1002/ceat.200401986

[9] Cheng, Y., Lien, F. S., Yee, E., Sinclair, R. (2003). A comparison of large Eddy simulations with a standard $k-\varepsilon$ Reynoldsaveraged Navier-Stokes model for the prediction of a fully developed turbulent flow over a matrix of cubes. Journal of Wind Engineering and Industrial Aerodynamics, 91 (11), 1301-1328. doi: https://doi.org/10.1016/j.jweia.2003.08.001

[10] Morad, A. M. A. (2018). A Two-Phase Pressure Drop Model for Homogenous Separated Flow for Circular Tube Condenser, Examined with Four Modern Refrigerants. Journal of Advanced Research in Fluid Mechanics and Thermal Sciences, 52 (2), $274-287$.

[11] Walters, D. K., Cokljat, D. (2008). A Three-Equation Eddy-Viscosity Model for Reynolds-Averaged Navier-Stokes Simulations of Transitional Flow. Journal of Fluids Engineering, 130 (12). doi: https://doi.org/10.1115/1.2979230

[12] Ma, J. M., Peng, S.-H., Davidson, L., Wang, F. J. (2011). A low Reynolds number variant of partially-averaged NavierStokes model for turbulence. International Journal of Heat and Fluid Flow, 32 (3), 652-669. doi: https://doi.org/10.1016/ j.ijheatfluidflow.2011.02.001

[13] Kim, J., Yadav, M., Kim, S. (2014). Characteristics of Secondary Flow Induced by 90-Degree Elbow in Turbulent Pipe Flow. Engineering Applications of Computational Fluid Mechanics, 8 (2), 229-239. doi: https://doi.org/10.1080/19942060.2014.11015509

[14] Lee, M. W., Yu, K. H., Teoh, Y. H., Lee, H. W., Ismail, M. A. (2019). Developing Flow of Power-Law Fluids in Circular Tube Having Superhydrophobic Transverse Grooves. Journal of Advanced Research in Fluid Mechanics and Thermal Sciences, 56 (1).

[15] Fox, R. W., McDonald, A. T., Pritchard, P. J. (2004). Introduction to fluid mechanics. John Wily \& Sons INC.

[16] Application of Direct and Large Eddy Simulation to Transition and Turbulence (1994). AGARD. North Atlantic Treaty Organization.

[17] COMSOL 5.4 Software, Guide, Multiphysics 2018.

[18] FLUENT 16.1 Software, Guide, ANSYS 2013.

[19] Thakre, S. S., Joshi, J. B. (2002). Momentum, mass and heat transfer in single-phase turbulent flow. Reviews in Chemical Engineering, 18 (2-3), 83-293. doi: https://doi.org/10.1515/revce.2002.18.2-3.83 